\title{
Uji Eksperimental Variasi Kadar Semen Terhadap Nilai CBR Tanah Lempung Yang Distabilisasi Dengan Semen
}

\author{
Iqbal $^{1}$, Rokhman $^{2}$ \\ ${ }^{1}$ Mahasiswa Program Studi Teknik Sipil Universitas Muhammadiyah Sorong \\ ${ }^{2}$ Dosen Program Studi Teknik Sipil Universitas Muhammadiyah Sorong
}

\begin{abstract}
Abstrak
Karakteristik tanah di wilayah kabupaten sorong terdiri dari tekstur halus, sedang dan kasar serta terdapat tanah gambut. Bagian terbesar atau mayoritas tekstur tanah di kabupaten sorong adalah tekstur halus. Jenis tanah ini daya dukungnya rendah apabila dijadikan untuk tanah dasar (subgrade). Untuk mengatasi permasalahan ini, salah satu usaha yang dilakukan untuk peningkatan daya dukung tanah tersebut adalah dengan melalui perbaikan tanah dengan metode stabilisasi menggunakan bahan adiktif salah satunya adalah semen. Jenis tanah diambil di daerah kampung wen distrik mayamuk kabupaten sorong. Contoh tanah ini akan dicampur dengan semen untuk kemudian diketahui karakteristik daya dukungnya berdasarkan uji CBR. Pada penelitian ini, penambahan semen akan dilakukan pada kadar 5\%, 10\%, 15\%, dan $20 \%$ dari total berat kering tanah. Sebelum melakukan pengujian CBR terlebih dahulu sampel tanah yang telah dipadatkan diperam selama 7 hari pada kondisi kadar air optimum. Dari hasil pengujian CBR menunjukkan bahwa seiring penambahan semen telah meningkatkan daya dukung tanah secara signifikan, Nilai CBR semakin naik seiring penambahan semen, dimana nilai CBR tanah asli sebesar 20,45\% terjadi peningkatan nilai CBR pada campuran $20 \%$ semen dengan waktu pemeraman 7 hari dengan nilai CBR sebesar 111,93\%
\end{abstract}

Kata kunci : tanah lempung, stabilisasi tanah, semen, CBR

\section{Pendahuluan}

Menurut irwanto (2016), Karakteristik tanah di wilayah kabupaten sorong terdiri dari tekstur halus, sedang dan kasar, serta terdapat tanah gambut. Bagian terbesar atau mayoritas tekstur tanah di kabupaten sorong adalah tekstur halus. Ukuran butir tanah halus, kurang dari 0,002 mm. jenis tanah ini daya dukungnya rendah apabila dijadikan untuk tanah dasar (subgrade) dalam pembangunan jalan. Kalau tanah yang digunakan kurang baik maka harus dilakukan treatment tambahan antara lain pemadatan, penggunaan geotekstil atau stabilisasi.

Karena seringkali tidak ada pilihan untuk material timbunan, sehingga tanah dengan plastisitas tinggi (jenis tanah lempung). digunakan sebagai material timbunan. Untuk mengatasi permasalahan ini, salah satu usaha yang dilakukan untuk peningkatan daya dukung tanah tersebut adalah dengan melalui perbaikan tanah dengan metode stabilisasi. Stabilisasi tanah dapat dilakukan dengan menambahkan berbagai jenis material kimiawi yang salah satunya adalah dengan menambahkan bahan seperti semen.

\section{Metode Penelitian}

Metode penelitian yang dilakukan dapat dilihat pada Gambar 1 berikut ini.

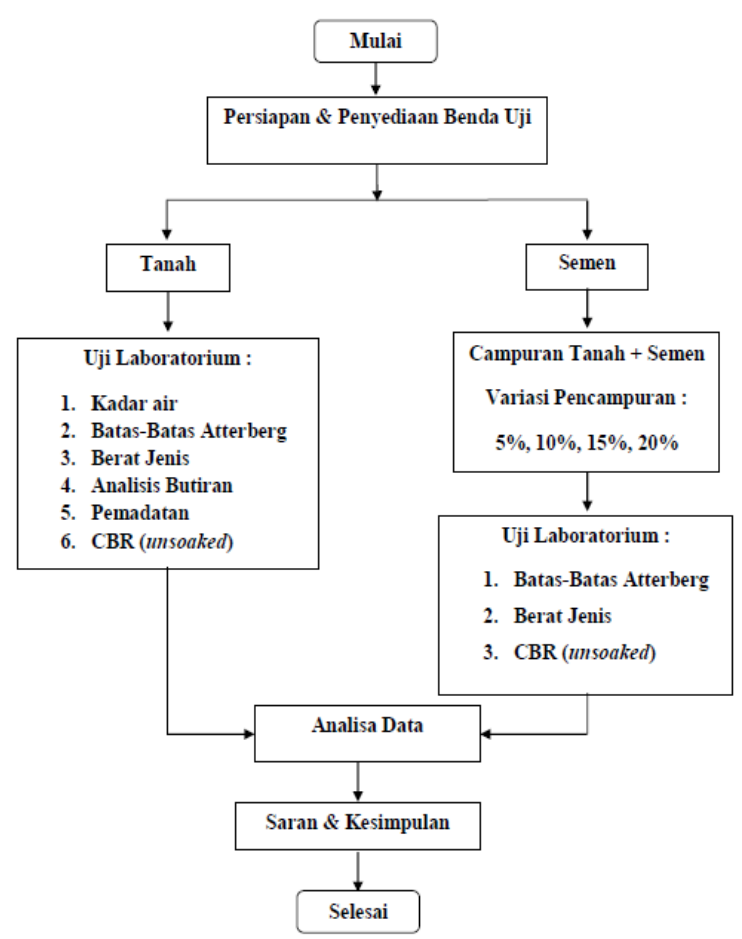

Gambar 1. Diagram alir penelitian

3. Hasil dan Pembahasan

Hasil Pengujian Sifat Fisik Dan Mekanik

Tanah Asli

Hasil pengujian sifat fisik dan mekanik tanah asli dapat dilihat pada Tabel 1 . 
Tabel 1. Hasil pengujian sifat fisik dan mekanik tanah asli kampung wen

\begin{tabular}{clc}
\hline No & \multicolumn{1}{c}{ Pemeriksaan } & Nilai \\
\hline 1 & Berat Jenis tanah $(\mathrm{Gs})\left(\mathrm{gram} / \mathrm{cm}^{3}\right)$ & 2.58 \\
2 & Batas Cair (LL) $(\%)$ & 51.6 \\
3 & Batas Plastis (\%) & 17.87 \\
4 & Indeks Plastisitas (Ip) (\%) & 33.73 \\
5 & Kadar Air Opt. (W opt) $(\%)$ & 20 \\
6 & CBR & 20.45 \\
\hline
\end{tabular}

Hasil Uji Sifat Fisik dan Mekanik Tanah Lempung dan Semen

Hasil uji sifat fisik dan mekaniik campuran tanah lempung dengan semen untuk kadar campuran 5\%, $10 \%, 15 \%$ dan $20 \%$ dapat dilihat pada tabel 2 .

Tabel 2. Hasil pengujian sifat fisik dan mekanik tanah asli dengan semen

\begin{tabular}{clccccc}
\hline No & Pengujian & $\begin{array}{c}\text { Tanah } \\
\text { Asli }\end{array}$ & $\mathbf{5 \%}$ Semen & $\mathbf{1 0 \%}$ Semen & $\mathbf{1 5 \%}$ Semen & $\begin{array}{l}\mathbf{2 0} \% \\
\text { Semen }\end{array}$ \\
\hline 1 & Berat Jenis $\left(\mathrm{gr} / \mathrm{cm}^{3}\right)$ & 2,58 & 2,60 & 2,62 & 2,65 & 2,68 \\
2 & Batas Cair $(\%)$ & 51,60 & 47,00 & 45,00 & 43,00 & 41,50 \\
3 & Batas Plastis $(\%)$ & 17,87 & 22,84 & 31,19 & 31,57 & 32,53 \\
4 & Indeks Plastisitas $(\%)$ & 33,73 & 24,16 & 13,81 & 11,43 & 8,97 \\
8 & CBR Laboratorium $(\%)$ & 20,45 & 79,92 & 91,74 & 103,26 & 111,93 \\
\hline
\end{tabular}

Berdasarkan data hasil pengujian dapat diklasifikasikan sifat tanah berdasarkan atas beberapa sistem klasifikasi yang ada yaitu :

1. Sistem klasifikasi AASHTO

Dilihat klasifikasi tanah menurut AASHTO dengan batasan - batasannya antara lain, dimana persentase lolos saringan no 200 lebih dari $35 \%$, nilai batas cairnya(LL) lebih dari $41 \%$ dan nilai indeks plastisitas (PI) lebih besar dari $11 \%$ tetapi lebih besar dari pada nilai batas cair (LL) dikurangi 30 .

- Lolos saringan no $200=51,04 \%$

- Batas cair $(\mathrm{LL})=51,60 \%$

- Indeks plastisitas (PI) $=33,73 \%$

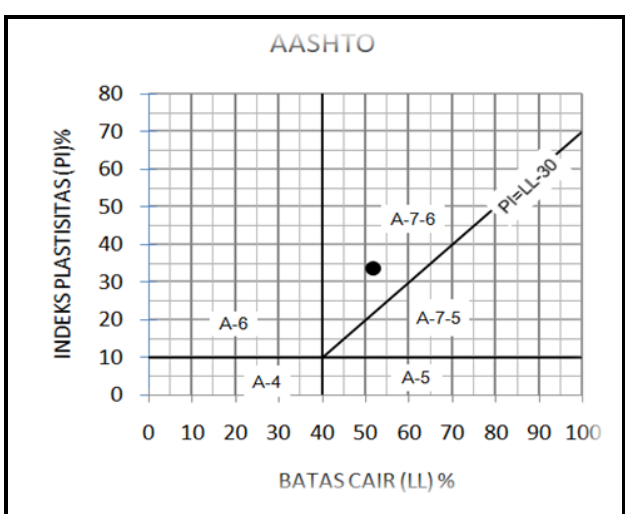

Gambar 2. Grafik hubungan plastis indeks dan liquid limit menurut AASHTO

Dari Gambar 2 diatas. Menurut sistem klasifikasi AASHTO termasuk dalam jenis kelompok tanah A-76 yaitu tipe material yang dominan adalah tanah berlempumg sedang sampai buruk.( Soedarmo G. Djatmiko, Purnomo S. J. Edy, 1997)

\section{Sistem klasifikasi USCS}

Sistem klasifikasi ini paling banyak diaplikasikan pada pengujian tanah. Sistem klasifikasi USCS. Adapun hasil dari pengujian laboratorium menunjukkan data properties tanah yang diperoleh adalah :

- Tanah yang lolos saringan no. $200=51.04 \%$

- Batas Cair (LL) = 51,60\%

- Indeks plastisitas (IP) $=33,73 \%$

Dari data properties tanah yang diperoleh diatas maka dapat disimpulkan beberapa hal, yaitu :

a. Berdasarkan nilai persentase lolos saringan no.200 tanah lempung diatas, persentase tersebut lebih besar dari 50\%, maka berdasarkan tabel klasifikasi USCS tanah ini secara umum dikategorikan golongan tanah berbutir halus.

b. Dari tabel sistem klasifikasi USCS untuk data batas cair dan indeks plastisitas diplotkan pada diagram plastisitas sehingga didapatkan identifikasi tanah yang lebih spesifik (Soedarmo G. Djatmiko, Purnomo S. J. Edy, 1997)

Hasil dapat dilihat pada gambar 3.

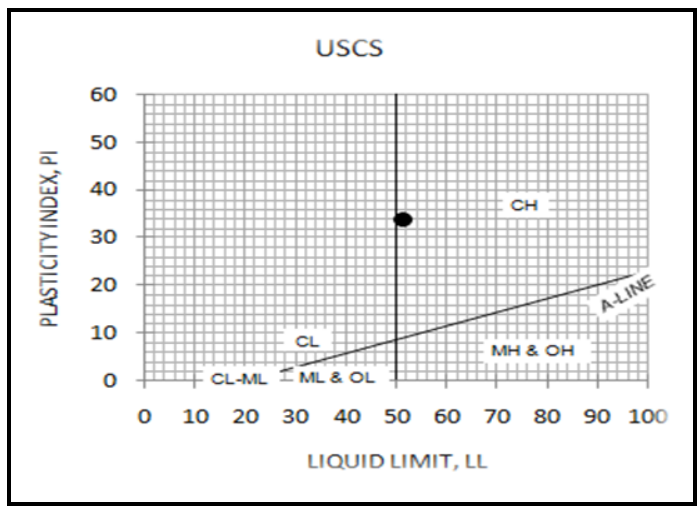

Gambar 3. Grafik hubungan indeks plastisitas dan batas cair USCS

Dengan merujuk pada gambar diatas maka tanah berbutir halus daerah kampung wen distrik mayamuk kabupaten sorong termasuk kedalam kelompok $\mathrm{CH}$ 
yaitu tanah lempung anorganik dengan plastisitas tinggi, lempung gemuk dengan nilai indeks plastisitas sebesar 33,73\% (plastisitas tinggi).

Perbandingan Sifat Fisik Dan Mekanik Tanah Lempung Dengan Campuran Semen

Berikut ini adalah Tabel 3 dan Gambar 4 yang menunjukan pengaruh sifat fisik dan mekanik tanah lempung dengan semen

\section{Hasil Uji Berat Jenis}

Pada pengujian berat jenis tanah lempung dengan campuran semen dapat terlihat bahwa nilai berat jenis semakin meningkat seiring bertambahnya kadar pencampuran semen, seperti terlihat pada Gambar 4.

Tabel 3. Berat jenis campuran tanah dengan semen

\begin{tabular}{ccc}
\hline No & $\begin{array}{c}\text { Kadar Semen } \\
(\boldsymbol{\%})\end{array}$ & $\begin{array}{c}\text { Hasil } \\
\left(\mathbf{g r} / \mathbf{c m}^{\mathbf{3}}\right)\end{array}$ \\
\hline 1 & 0 (Tanah Asli) & 2.58 \\
2 & 5 & 2.60 \\
3 & 10 & 2.62 \\
4 & 15 & 2.65 \\
5 & 20 & 2.68 \\
\hline
\end{tabular}

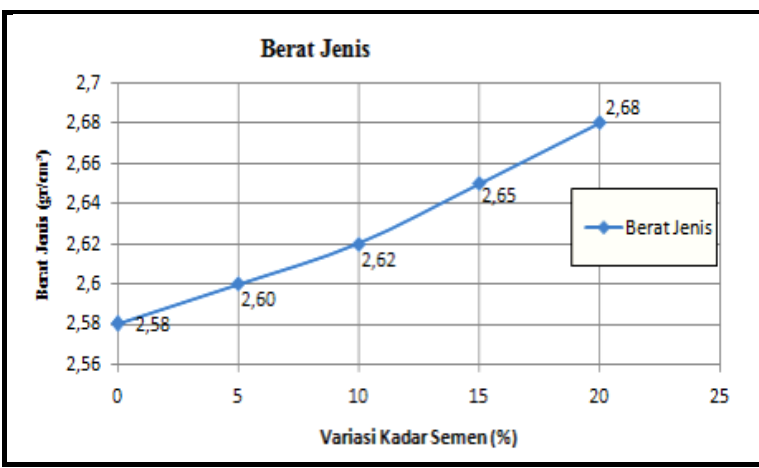

Gambar 4. Grafik Pengaruh kadar semen terhadap nilai berat jenis.

Dari Gambar 4. hasil pengujian berat jenis tanah tanah ditambah dengan campuran semen dengan persentase $5 \%, 10 \%, 15 \%$ dan $20 \%$ terjadi peningkatan nilai berat jenis tanah dibandingkan dengan berat jenis tanah asli yaitu $2,58 \mathrm{gram} / \mathrm{cm}^{3}$

\section{Hasil Uji Atterberg}

Hasil pengujian Atterberg tanah lempung dengan campuran semen dapat dilihat pada Tabel 4, sedangkan pengaruh penambahan semen terhadap nilai nilai batas cair (LL), batas plastis (PL) dan indeks plastisitas (IP) dapat dilihat pada Gambar 5.

Dari gambar 5 di atas dapat dilihat dari hasil pengujian atterberg limit setelah penambahan semen, terlihat bahwa semakin tinggi kadar semen maka batas plastis (PL) meningkat sedangkan batas cair (LL) menurun, sehingga indeks plastisitas (IP) tanah menurun. Selain itu unsur kimia dari semen disinyalir bercampur dengan air membentuk pasta yang mengikat partikel lempung dan mampu menutupi pori-pori tanah membuat air sulit menyerap dalam campuran tanah semen sehingga mampu menurunkan sifat plastisnya.

Tabel 4.Batas-batas atterberg

\begin{tabular}{ccccc}
\hline No & $\begin{array}{c}\text { Kadar Abu } \\
\text { Sekam }(\boldsymbol{\%})\end{array}$ & $\begin{array}{c}\text { LL } \\
(\boldsymbol{\%})\end{array}$ & $\begin{array}{c}\text { PL } \\
(\boldsymbol{\%})\end{array}$ & $\begin{array}{c}\text { IP } \\
(\boldsymbol{\%})\end{array}$ \\
\hline 1 & 0 & 51.60 & 17.87 & 33.73 \\
2 & 5 & 47.00 & 22.84 & 24.16 \\
3 & 10 & 45.00 & 31.19 & 13.81 \\
4 & 15 & 43.00 & 31.57 & 11.43 \\
5 & 20 & 41.50 & 32.53 & 8.97
\end{tabular}

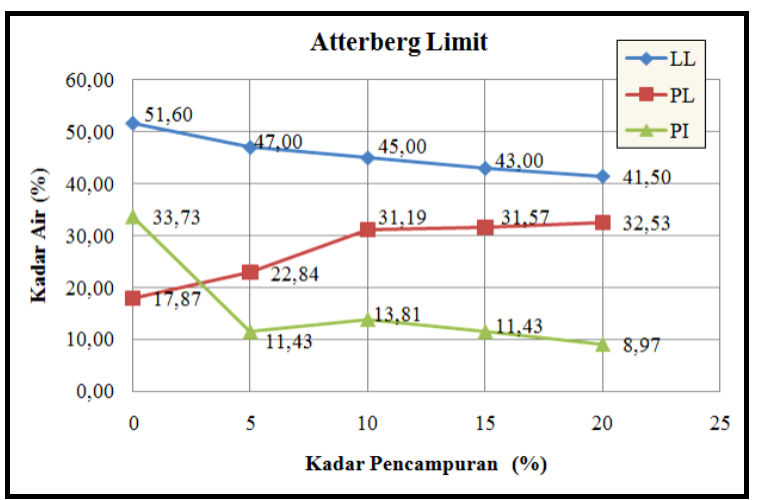

Gambar 5. Pengaruh Penambahan semen terhadap nilai Batas Cair, Batas Plastis, Dan indeks plastisitas

(IP)

\section{Hasil Uji CBR}

Hasil dari pengujian CBR tanah lempung dengan campuran semen dapat dilihat pada Tabel 5 dan Gambar 6

Tabel 5. Hasil pengujian CBR pada tanah plus abu sekam

\begin{tabular}{ccc}
\hline No & $\begin{array}{c}\text { Kadar Abu Sekam } \\
(\boldsymbol{\%})\end{array}$ & CBR (\%) \\
\hline 1 & 0 (Tanah Asli) & 20.45 \\
2 & 5 & 79.92 \\
3 & 10 & 91.74 \\
4 & 15 & 103.26 \\
5 & 20 & 111.93 \\
\hline
\end{tabular}

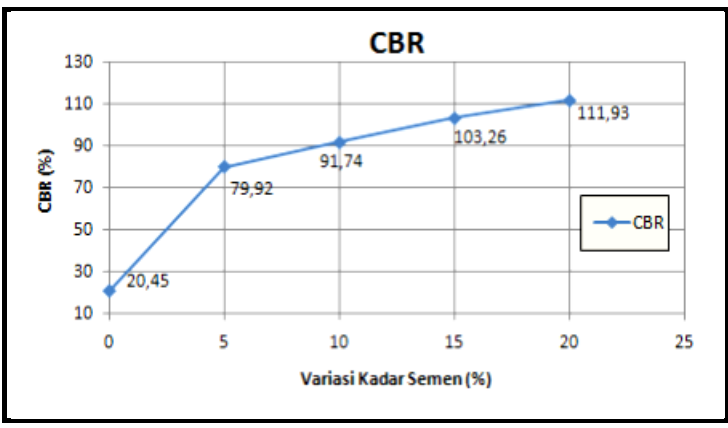

Gambar 6. Grafik Pengaruh Penambahan semen terhadap Nilai CBR Tanah Asli 
Dari hasil pengujian dan gambar diatas, dapat dilihat bahwa seiring penambahan kadar variasi semen telah meningkatkan nilai CBR tanah lempung pada pemeraman 7 hari secara signifikan. Hal ini diakibatkan oleh reaksi sementasi yang terjadi pada campuran semen membentuk butiran baru yang lebih keras sehingga lebih kuat menahan beban yang diberikan.

\section{Perbandingan Terhadap Penelitian Terdahulu}

Penulis membandingkan hasil-hasil pengujian tanah campuran semen yang diteliti oleh Andriani, Rina yuliet, franky Leo Fernandez (2012). Hasil-hasil pengujian dapat dilihat pada Tabel 6. Dan Perbandingan nilai CBR penambahan semen terhadap pengujian terdahulu dapat dilihat pada Gambar 7.

Tabel 6. Perbandingan hasil-hasil pengujian

\begin{tabular}{|c|c|c|c|c|c|c|c|c|c|c|c|c|}
\hline \multirow[t]{3}{*}{$\begin{array}{c}\text { KADAR } \\
\text { SEMEN } \\
(\%) \\
\end{array}$} & \multicolumn{2}{|c|}{$\begin{array}{l}\text { PEMERAMAN } \\
\text { (hari) }\end{array}$} & \multicolumn{10}{|c|}{ PENGUJIAN } \\
\hline & \multirow[b]{2}{*}{ A } & \multirow[b]{2}{*}{ B } & \multicolumn{2}{|c|}{ GS $\left(\mathrm{gr} / \mathrm{cm}^{3}\right)$} & \multicolumn{2}{|c|}{ LL (\%) } & \multicolumn{2}{|c|}{ PL (\%) } & \multicolumn{2}{|c|}{ PI (\%) } & \multicolumn{2}{|c|}{ CBR (\%) } \\
\hline & & & A & B & A & B & A & B & A & B & A & B \\
\hline 0 & 3 & 7 & 2,58 & 2,58 & 82,84 & 51,60 & 56,29 & 17,87 & 26,55 & 33,73 & 8,20 & 20,45 \\
\hline 5 & 3 & 7 & 2,59 & 2,60 & 70,79 & 47,00 & 61,35 & 22,84 & 9,43 & 24,16 & 24,61 & 79,92 \\
\hline 10 & 3 & 7 & 2,60 & 2,62 & 64,96 & 45,00 & 60,25 & 31,19 & 4,57 & 13,81 & 43,25 & 91,74 \\
\hline 15 & 3 & 7 & 2,61 & 2,65 & 64,62 & 43,00 & 59,22 & 31,57 & 5,39 & 11,43 & 55,93 & 103,26 \\
\hline 20 & 3 & 7 & 2,64 & 2,68 & 73,26 & 41,50 & 59,64 & 32,53 & 13,62 & 8,97 & 64,13 & 111,93 \\
\hline
\end{tabular}

Keterangan :

Untuk A : Andriani, Rina Yuliet, FRanky Leo Fernandes (2012)

Untuk B : Iqbal (2017)

- GS : : Spesific Gravity (Berat Jenis)

- LL : Liquid Limit

-PL : Plastic Limit

- PI : Plastisitas Index

- CBR : California Bearing Ratio

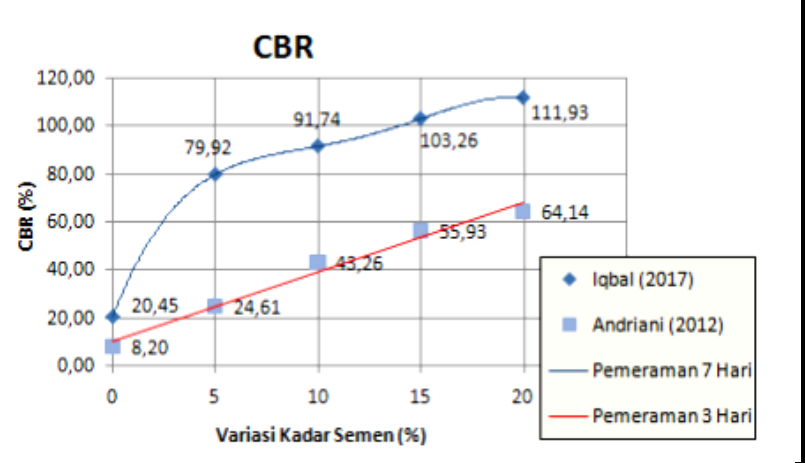

Gambar 7. Grafik Perbandingan nilai CBR terhadap pengujian terdahulu

Dari gambar diatas dapat dilihat bahwa pengaruh penambahan semen telah meningkatkan nilai CBR secara signifikan. Dimana seiiring bertambahnya kadar campuran semen dan waktu pemeraman, nilai CBR semakin meningkat.

\section{Kesimpulan}

Dari hasil penelitian yang telah dilakukan dapat diperoleh beberapa kesimpulan sebagai berikut :

a. Indeks propertis tanah asli menunjukkan nilai berat jenis tanah asli $(\mathrm{GS})=2,58 \mathrm{grcm}^{3}$, Batas Cair $(\mathrm{LL})=51,60 \%$, Batas Plastis $(\mathrm{PL})=17,87 \%$ dan Indeks Plastisitas (PI) $=33,73 \%$. Seiring dengan penambahan semen dengan variasi penambahan sebesar 5\%, 10\%, $15 \%$ dan $20 \%$ telah meningkatkan nilai berat jenis masingmasing menjadi 2,60, 2,62, 2,65 dan 2,68. sedangkan untuk nilai indeks plastisitasnya semakin menurun masing-masing menjadi $24,16 \%, 13,81 \%, 11,43 \%$ dan $8,97 \%$

b. Pengaruh penambahan semen telah meningkatkan nilai daya dukung tanah secara signifikan. Nilai CBR semakin naik seiring penambahan semen, dimana nilai CBR tanah asli sebesar $20,45 \%$ terjadi peningkatan nilai CBR pada campuran $20 \%$ semen dengan waktu pemeraman 7 hari dengan nilai CBR sebesar $111,93 \%$.

\section{Referensi}

Andriani, Yuliet. R, Fernandez. L 2012, Pengaruh penggunaan semen sebagai bahan stabilisasi pada tanah lempung daerah lambung bukit terhadap nilai CBR tanah, Jurnal ISSN:18582133 Vol 8 No. 1

Hardiyatmo. H. C. , 1992, Mekanika Tanah 1 Edisi Ke- dua, Universitas Gajah Mada, Yogyakarta.

Soedarmo G. Djatmiko, Purnomo S. J. Edy, 1997, Mekanika Tanah 1, Yogyakarta.

http://irwanto.info/gambaran-umum-kabupatensorong-provinsi-papua-barat/ 